\title{
Correr para vivir: el dilema rarámuri
}

\author{
Ángel Acuña Delgado
}

“QQuien no aguanta, no vale!”, dice un viejo principio rarámuri, grupo étnico ubicado en la Sierra Tarahumara, dentro de la Sierra Madre Occidental del estado de Chihuahua, en México. Inmerso en un entorno ambiental ecológicamente duro para la supervivencia, se asume la idea de que "para vivir hay que ser resistente", para poder soportar la falta de agua y alimentos provocada por la sequía, el intenso frío nocturno del invierno o las largas travesías por la montaña. Desde centenares de años, hombres y mujeres rarámuris, como dicta la costumbre, compiten corriendo ininterrumpidamente día y noche, por terrenos pedregosos y abruptos, distancias que llegan a superar los $200 \mathrm{~km}$. En el presente trabajo se describe a grandes trazos distintos aspectos de esta singular carrera, para analizar después las funciones principales que cumple como acontecimiento cultural.

"If you don't endure, you're worthless!" says an old Raramuri principle. This etnic group lives in the Sierra Tarahumara, located in the Sierra Madre Occidental in the State of Chihuahua in Mexico. Immerse in an ecologically tough environment for survival, it is assumed that "to survive you must be resistant"; put up with water and food shortage provoked by drought, intense night cold in winter, and long treks across the mountains. For centuries, Raramuri men and women, as the tradition dictates, compete running uninterruptedly during day and night, on rocky and difficult land, along distances that can be over two hundred kilometers long. This paper outlines the diverse traits of a unique race, and then analyses the principal functions that it accomplishes as cultural event.

ÁNGEl ACUÑa DELGADO: Universidad de Granada. 
$\mathrm{E}$ n el presente trabajo, tras hacer algunas observaciones sobre la carrera de larga distancia en la historia de las culturas, a modo de introducción, y una breve reseña etnográfica sobre el grupo en cuestión, se describe a grandes trazos distintos aspectos de esta singular carrera, para a continuación analizar las funciones principales que cumple como acontecimiento cultural y reflexionar sobre uno de sus principales valores: la resistencia. De este modo, procuraremos responder a interrogantes tales como: ¿por qué corren así los rarámuris?, ¿por qué se cubren tan largas distancias?, ¿cómo se explica la actitud mesurada de los corredores ante la victoria $\mathrm{o}$ ante la derrota?, ¿qué papeles desempeña la carrera en la vida rarámuri?, ¿qué valor tiene la resistencia?, ¿cómo se consigue desarrollar?, ¿cómo se asume la participación rarámuri en ultramaratones internacionales?

\section{LA CARRERA DE LARGA DISTANCIA EN LA HISTORIA DE LAS CULTURAS}

Son muchas las referencias que se tienen sobre la carrera de larga distancia en la historia de las culturas y de todas ellas el pedestrismo griego figura en primera línea. En la $113^{\text {va }}$ Olimpiada de la Antigüedad, se dice de Agon de Argos que después de haber triunfado en la carrera de larga distancia, ese mismo día se regresó corriendo a su ciudad, situada a unos $100 \mathrm{~km}$ para dar la noticia. También Drymos, acto seguido de su victoria olímpica, recorrió más de $140 \mathrm{~km}$ hasta su lugar de residencia. Euchidas de Platea, tras la derrota de los persas, recorrió en un solo día los $190 \mathrm{~km}$ de ida y vuelta a Delfos, para renovar el fuego del altar de Apolo profanado por los persas. En el 490 a.C. quedó inmortalizada la carrera que un correo griego hizo desde Marathon hasta Atenas, cubriendo una distancia de $42 \mathrm{~km}$ para dar la noticia de la victoria obtenida sobre los persas; según cuenta la leyenda, el corredor murió agotado tras cumplir el encargo. La tropa ateniense en la campaña contra Darío recorrió en formación cerrada $230 \mathrm{~km}$ durante tres días y tres noches (Diem, C., 1966: 141-146).

En otro contexto espacial y temporal, las carreras de relevos de los "chasquis" (correos incas) hacían posible

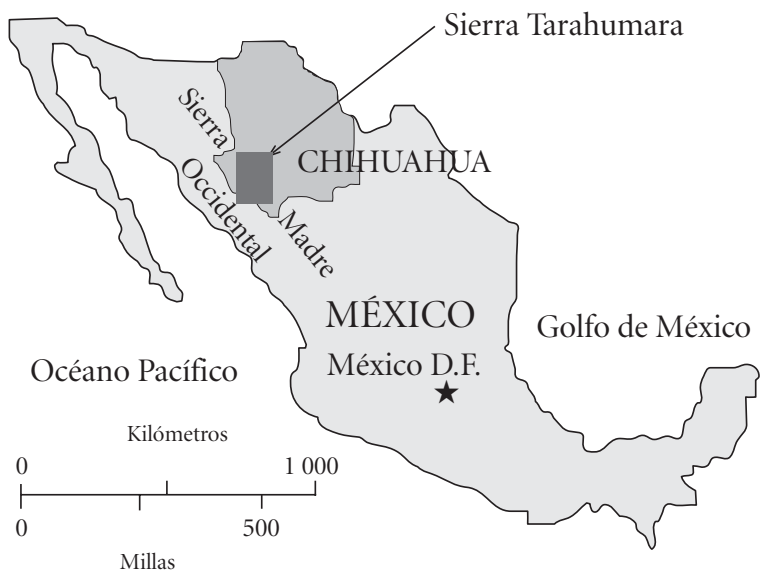

que las noticias entre Quito y Cuzco (separados unos $1600 \mathrm{~km}$ ) llegaran en ocho días. Los hotentotes y los bosquimanos en África del Sur han sido caracterizados ${ }^{1}$ como potentes corredores que practicaban la caza de persecución para capturar animales a la carrera. Los seris del golfo de California o los huicholes de la meseta mexicana también se citan como potentes marchadores y corredores, capaces de cazar a la carrera liebres y ciervos. ${ }^{2}$ Los guaraníes sudamericanos cazaban a la carrera al ñandú ${ }^{3}$ y entre los aborígenes australianos se habla de hombres que han capturado canguros con las manos, corriendo tras ellos. ${ }^{4}$ Los sioux y otras tribus estadounidenses de las grandes praderas organizaban reuniones intertribales para competir corriendo. Los navajos de Nuevo México organizaban largas carreras para propiciar la lluvia y prosperidad de las plantas. ${ }^{5}$

Dentro del contexto europeo y como precedentes de las modernas carreras de competencia tenemos las carreras pedestres inglesas realizadas entre algunos sirvientes de la aristocracia llamados "footmen", quienes en el siglo XVI corrían al lado o delante de los carruajes para evitar

\footnotetext{
${ }^{1}$ Kolb, 1718; cfr. Weule, 1974: 294.

2 Weule, 1974: 300.

3 Friederici, 1942; cfr. Damm, 1973: 239.

${ }^{4}$ Howitt, 1904; cfr. Damm, 1973: 240.

5 Culin, 1907; cfr. Damm, 1973: 236.
} 
que se ladearan peligrosamente y para guiar a las caballerías por entre los malos tramos del camino. ${ }^{6}$

Más tarde, en el último cuarto del siglo XIX, tomaron mucho auge las carreras de largo recorrido, animadas por la competencia entre los corredores profesionales de Inglaterra y Estados Unidos. O'Leary en 1876 ganó una carrera de seis días recorriendo $836 \mathrm{~km}$, distancia que se fue superando año tras año para que en 1888 Littlewood impusiera el récord en $1003 \mathrm{~km}$ con un promedio de $167 \mathrm{~km}$ por día, a una velocidad media de $7.6 \mathrm{~km}$ por hora (al descansar un total de 15 horas y 19 minutos). ${ }^{7}$ Weston, en 1909, con 71 años de edad, recorrió en 105 días el trayecto de $6270 \mathrm{~km}$, durante su dedicación a la carrera de competencia recorrió unos $136800 \mathrm{~km}$ (Diem, 1966: 133-134).

Correr grandes distancias no es nada nuevo, pero, ¿por qué todo esto? El deseo o el afán por superar algún "límite" ha sido y es una constante en la historia humana. La participación en carreras de largo recorrido, bien sea para ganar, para rebajar tiempo, o simplemente para llegar, de acuerdo con la capacidad física y mental de cada uno, es un reto para muchos, el cual supone probarse a de ser mejor. Pero, además, las carreras ultralargas en la sociedad moderna avanzada se han convertido en un recurso para crear vínculos de identidad, espacios de interacción que compensen la falta de compartir, de encuentro y comunicación social existente en la vida diaria. Participar en carreras que exigen una gran resistencia física es utilizado por no pocas personas como una manera inconciente de adscribirse a un grupo de iguales que comparten la sensación de haberlo logrado, de haber demostrado autenticidad a través del sacrificio corporal.

Los motivos y los sentidos que se desprenden de las carreras ultralargas son, sin embargo, diversos al comparar sociedades con modelos culturales distintos, y en esa línea la carrera rarámuri (rarajípari y rowera), dentro de la categoría de carrera ultralarga, mantiene marcadas diferencias con respecto a las que se realizan en el contexto occidental, manteniéndose esa tradición aún viva.
6 Mandell, 1986: 150.

7 Diem, 1966: 133-134.
Karl Lumholtz (1904, 1972: 297) describió a los rarámuris de finales del siglo XIX como los corredores más resistentes del mundo. Cuenta de un hombre que en cinco días recorrió unas 600 millas (960 km) para llevar un mensaje desde Guazápares hasta Chihuahua. Cuenta también que capturaban a la carrera a caballos montaraces (salvajes) y perseguían a un venado durante varios días hasta capturarlo y darle muerte. Carl Diem (1973: 224) hace referencia a la hazaña de un rarámuri quien en 1932 recorrió a la manera tradicional (pateando una bola) $560 \mathrm{~km}$ ininterrumpidamente por terreno pedregoso y quebrado.

Actualmente los rarámuris siguen corriendo como siempre lo han hecho, y en los últimos diez años, sobre todo, algunos han sido invitados a competir en ultramaratones internacionales como las 100 millas de Colorado o de Los Ángeles, donde consiguen también ganar ante corredores profesionales, como ocurrió en 1993 con V. Churo, en 1994 con J. Herrera y en 1997 con Chacarito.

Existen, pues, pruebas del pasado y del presente que acreditan a los rarámuris como un pueblo de corredores, los cuales poseen una gran capacidad de resistencia y dureza física, demostrada y reconocida en la actualidad, lo cual hace que lejos de las exageraciones la leyenda se haga historia.

\section{RESEÑA ETNOGRÁFICA}

El grupo étnico rarámuri actualmente habita al suroeste del estado de Chihuahua (México), territorio abrupto que adopta el nombre de Sierra Tarahumara dentro de la Sierra Madre Occidental. "La Tarahumara”, como se la denomina comúnmente, está formada por un macizo montañoso compuesto por picos, cañones y mesetas, cuya altitud oscila entre los 300 y los 3000 msnm (Amador, 1997: 17), extendiéndose por un territorio de unos $60000 \mathrm{~km}^{2}$ (Sariego, 2000: 13). Generalmente se distinguen dos zonas ecológicas claramente diferenciadas: la Alta y la Baja Tarahumara, también llamadas Sierra y Barranca, respectivamente.

La Alta Tarahumara es una región fría, llena de valles, mesetas y montañas. El clima es riguroso, aunque la media anual de temperatura puede ser de $18^{\circ}$ o $20^{\circ} \mathrm{C}$. Las 
diferencias adiabáticas del día a la noche pueden rondar $\operatorname{los} 30^{\circ} \mathrm{C}$; si bien en los días de verano se superan los $30^{\circ} \mathrm{C}$, en las noches de invierno desciende hasta los $-20^{\circ} \mathrm{C}$. La variabilidad en las precipitaciones es grande, dándose frecuentemente (cada diez u once años) graves sequías.

La Baja Tarahumara mantiene unas características contrastantes con la Alta; en sus profundas barrancas, entre las que destacan las de Urique, Batopilas, Sinforosa y el Cobre, crece una variada vegetación tropical. El clima es cálido y húmedo todo el año, sobrepasándose los $40^{\circ} \mathrm{C}$ en verano.

Las dos regiones mencionadas existentes en la Tarahumara ha permitido que muchas familias rarámuris varíen y combinen sus nichos ecológicos, cambiando de sitio a los rebaños y la propia residencia, de acuerdo con las exigencias del clima. ${ }^{8}$

Pertenecientes al grupo etnolingüístico uto-azteca (Bennett, W. y Zing, R., 1935, 1978: 357), al igual que otros grupos indígenas americanos, los rarámuris sufrieron la agresión de los conquistadores españoles y posteriormente de otros grupos vecinos como los apaches, sus rivales más fieros, así como de los mestizos y la sociedad nacional mexicana.

La importante colonización mestiza que ha sufrido la Tarahumara en el último siglo no ha traído en consecuencia una merma de la población rarámuri que, lejos de disminuir, resiste la presión y sigue aumentando su demografía. En la actualidad se estima que hay unos 50000 rarámuris diseminados por toda la sierra. La población mestiza, por su parte, es mayoría, con 201644 habitantes — 98677 en la Alta y 102967 en la Baja Tarahumara (INEGI, 1995).

Los rarámuris poseen un tipo físico de complexión vigorosa y porte esbelto, con estatura promedio de $1.65 \mathrm{~m}$ el hombre y de 1.58 m la mujer ${ }^{9}$ (Schalkwijk, 1985: 25). En general el tipo físico está bien proporcionado, destacando como cualidades la enorme resistencia al esfuerzo, la gran dureza para hacer frente a los rigores del ambien-

\footnotetext{
${ }^{8}$ Para más información sobre las características ambientales de la Sierra Tarahumara véase Mayer, 1996: 6-14; Amador, 1997: 17-22. ${ }^{9}$ La mujer es más robusta que el hombre.
}

te, soportando con poco abrigo las bajas temperaturas nocturnas, así como la capacidad para resistir el dolor físico provocado por las enfermedades, los traumatismos o el parto, sin mostrar queja.

Su estado de salud general se presenta, sin embargo, bastante precario. Las enfermedades más frecuentes son las derivadas del parasitismo, tanto interno (gastroenteritis, amebiasis), como externo (sarna, piojos), enfermedades venéreas, diarréicas agudas, infecciones respiratorias agudas y neumonía, entre otras, llaman especialmente la atención por el alto grado de desnutrición infantil (González, E., 1999; Oros, S., 2001).

La cultura material rarámuri de hoy representa un ejemplo de utilización inteligente de un medio ambiente bastante inhóspito. Al igual que en el pasado, su economía sigue siendo de subsistencia, orientada al autoconsumo y apoyada en la agricultura y el pastoreo, aunque con una disminución notable de la caza y la recolección. El maíz y el frijol constituyen la base de su alimentación.

Con toda la presión que desde hace siglos vienen ejerciendo distintos agentes aculturadores (Iglesia, Estado, sociedad rural mexicana, medios de comunicación) los rarámuris se han impregnado en mayor o menor grado de influencias foráneas. Los nuevos conocimientos, no obstante, se han incorporado a su modo de vida no sin antes haber sido "raramurizados", filtrados por su propia experiencia y modificados parcialmente para hacerlos significativos y útiles.

Aun siendo un pueblo no cerrado a lo que viene de fuera, permeable a las influencias exteriores, que ha hecho valer un claro sentido práctico al quedarse con todo aquello que ha considerado útil para mejorar o al menos mantener sus condiciones de vida, también es preciso señalar su actitud de resistencia a modificar los aspectos esenciales de su tradicional forma de entender el mundo y actuar sobre él.

Etimológicamente la palabra "rarámuri” significa "pie corredor" o "corredor a pie" (Bennett, W. y Zing, R., 1935; Amador, A., 1997: 17) y es precisamente la carrera una de sus peculiaridades culturales por la que son conocidos internacionalmente, la cual mantiene en la actualidad plena vigencia resistiéndose al cambio. De ella nos vamos a ocupar en las siguientes páginas, con base en el trabajo 


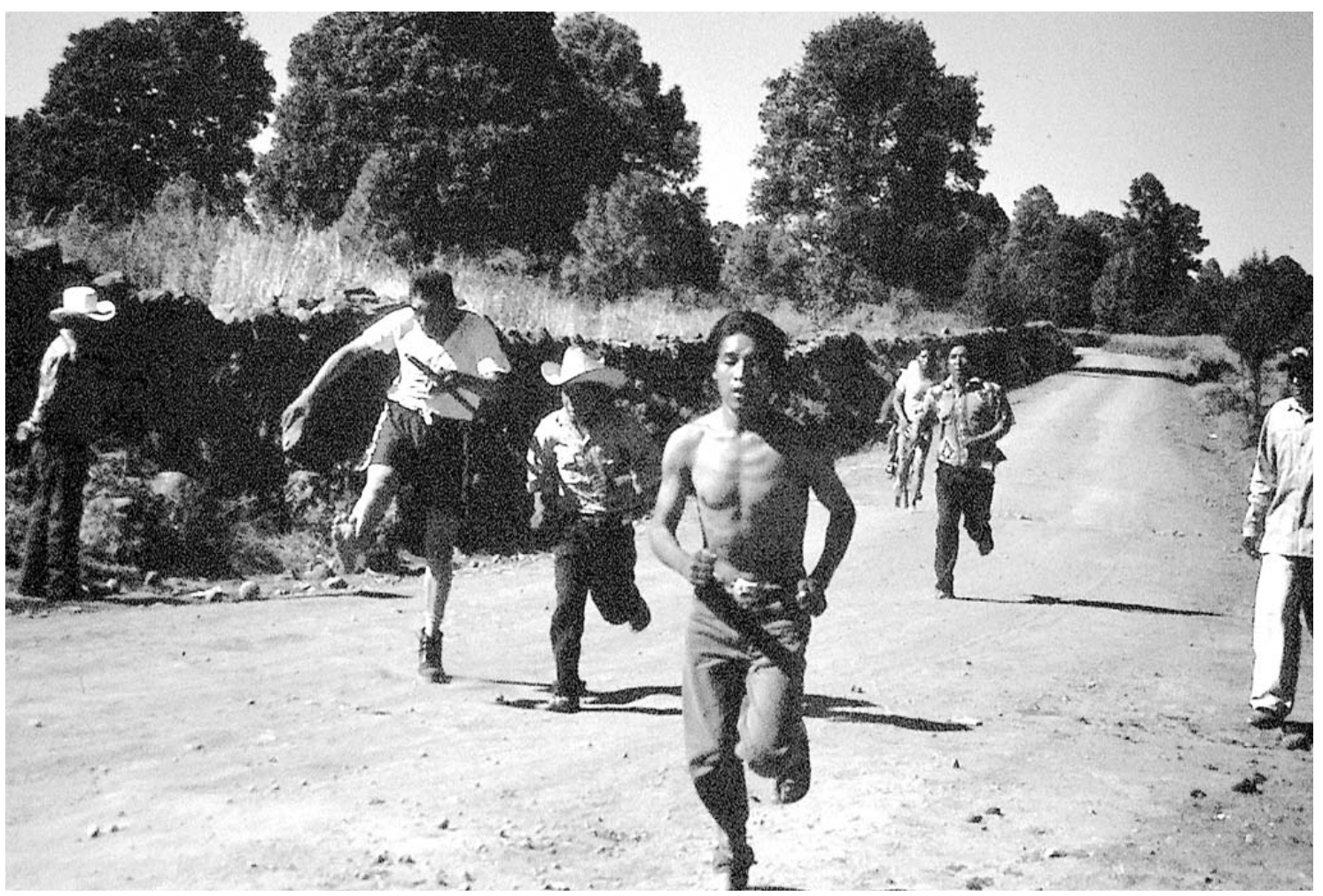

Carrera de bola en Cieneguita, octubre de 2001. Foto: Ángel Acuña Delgado.

de campo realizado durante los meses de octubre y noviembre de 2001 en distintas comunidades de la Alta Tarahumara. ${ }^{10}$

\section{DESCRIPCIÓN DE LA CARRERA RARÁMURI}

La tradicional carrera rarámuri posee dos modalidades denominadas: 1) rarajípari o carrera de bola para los hombres, y 2) rowera o carrera de ariwueta para la mujer. La bola se hace de la raíz del encino, madroño o tascate, tiene un diámetro de unos 7 u $8 \mathrm{~cm}$ y unos 230 gr de peso. El aro o ariweta está hecho de ramillas vegetales, con un

${ }^{10}$ Las comunidades visitadas durante la estancia fueron: Norogachi, Choguita, Tehuerichi, Panalachi, Sisoguichi, Narachárachi, Basíhuare, Rocheachi, Cieneguita, además de los municipios de Guachochi y Creel diámetro variable entre 5 y $15 \mathrm{~cm}$, estando ensartado doble en algunas zonas.

De acuerdo con el lenguaje utilizado por los propios rarámuris se pueden distinguir básicamente tres tipos de carrera: grandes, medianas y pequeñas, teniendo como criterios esenciales la duración de la misma y la cuantía de las apuestas acumuladas. Una gran carrera se suele concertar con semanas e incluso meses de antelación, tiene una duración de entre 15 y 20 horas para los hombres y entre 8 y 15 horas para las mujeres; los primeros cubren distancias de entre 100 y $200 \mathrm{~km}$, y las segundas entre 50 y $100 \mathrm{~km}$. Estas carreras levantan mucha expectación y un elevado monto de apuestas. La pequeña carrera se suele improvisar o concertar con poca antelación, es propia del juego de niños y niñas y también de los adultos dentro del contexto de las tesgüinadas (reuniones de trago); en ellas se pueden recorrer entre 2 y $10 \mathrm{~km}$ más o menos y las apuestas no son muy cuantiosas. Las medianas, por 


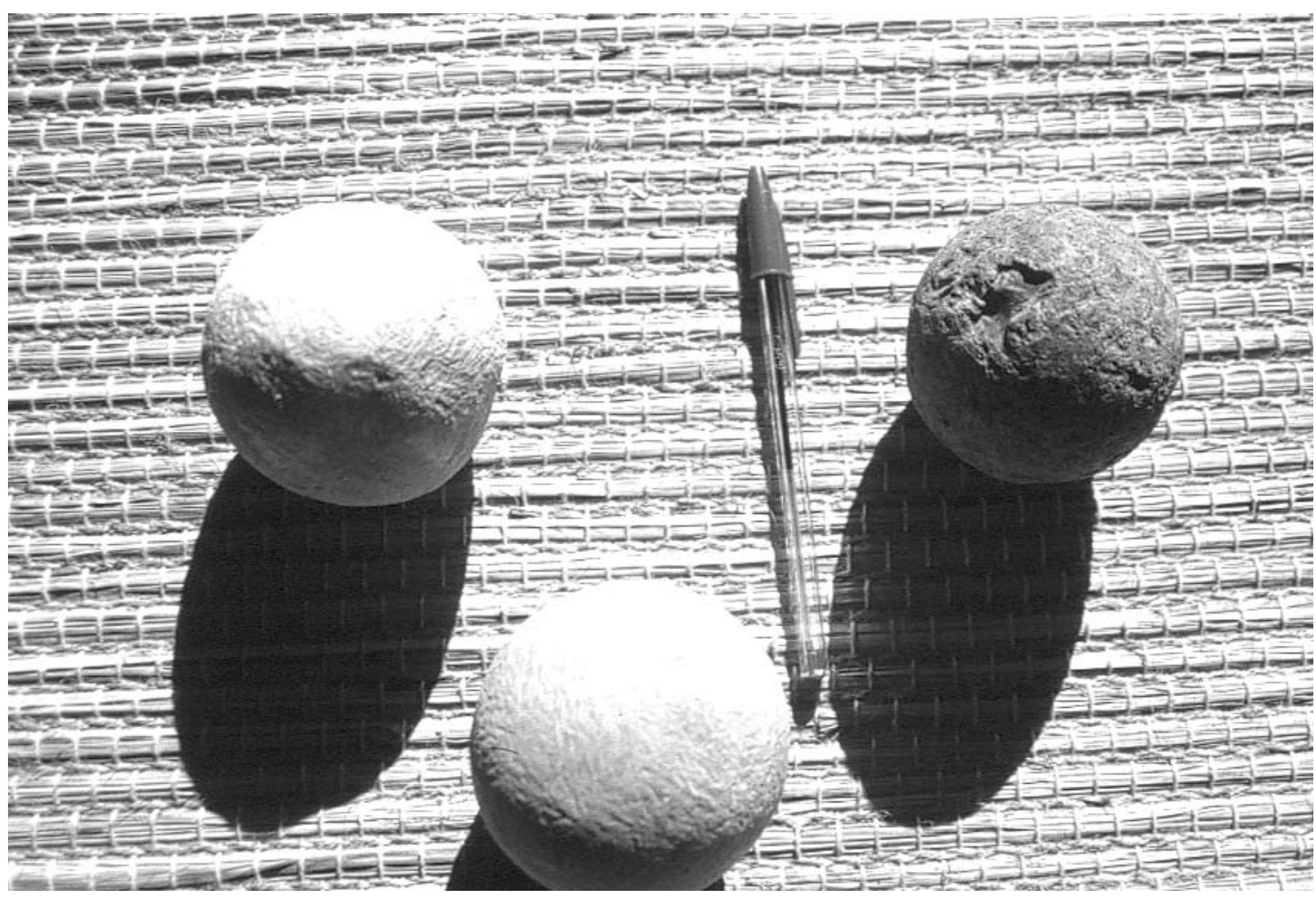

Bolas (komaka). Foto: Ángel Acuña Delgado.

su parte, ocuparían un amplio espectro, cubriendo distancias muy variables entre los extremos anteriores. Además hay que tener en cuenta la carrera "ceremonial" o "conmemorativa" realizada con motivo de la muerte de alguna persona; con ella se lleva a cabo un acto simbólico en el que se recorren unos centenares de metros como homenaje al fallecido o fallecida.

Cualquier época puede ser utilizada para organizar una carrera, aunque la inmensa mayoría de ellas se concentran entre el verano y el otoño (de mayo a septiembre), época en la que no hace tanto frío nocturno y el ambiente por el día se encuentra más húmedo por ser tiempo de lluvias.

El eje del sistema organizativo de una gran carrera es el chokéame u organizador principal de la misma. Pueden haber dos, uno por cada corredor o equipo enfrentado, y ser indistintamente hombre o mujer. Ellos se encargan de gestionar y negociar todos los extremos de la carrera, poniendo de acuerdo a los corredores, además de recoger y concertar las apuestas de la gente interesada.

En cuanto a la preparación y cuidados de los corredores antes de una gran carrera, los rarámuris no practican ninguna actividad especial, su forma física se basa en el entrenamiento natural que proporciona la vida diaria, al caminar mucho cuidando rebaños o visitando a gente. Los niños y jóvenes se desplazan con frecuencia corriendo, jugando con la bola o la ariweta, y será la selección natural la que haga de filtro para que con el tiempo los mejores participen en las grandes carreras y el resto lo hagan en las medianas o pequeñas.

Ante el reto de una gran carrera los corredores o corredoras deben llevar a cabo, eso sí, una serie de cuidados corporales, deben ser bien alimentados por sus respectivas familias, choquéames o vecinos que vayan a apostar por él o ella, evitar grandes esfuerzos, no participar en las tesgüinadas, y descansar bien unos días antes de la gran 


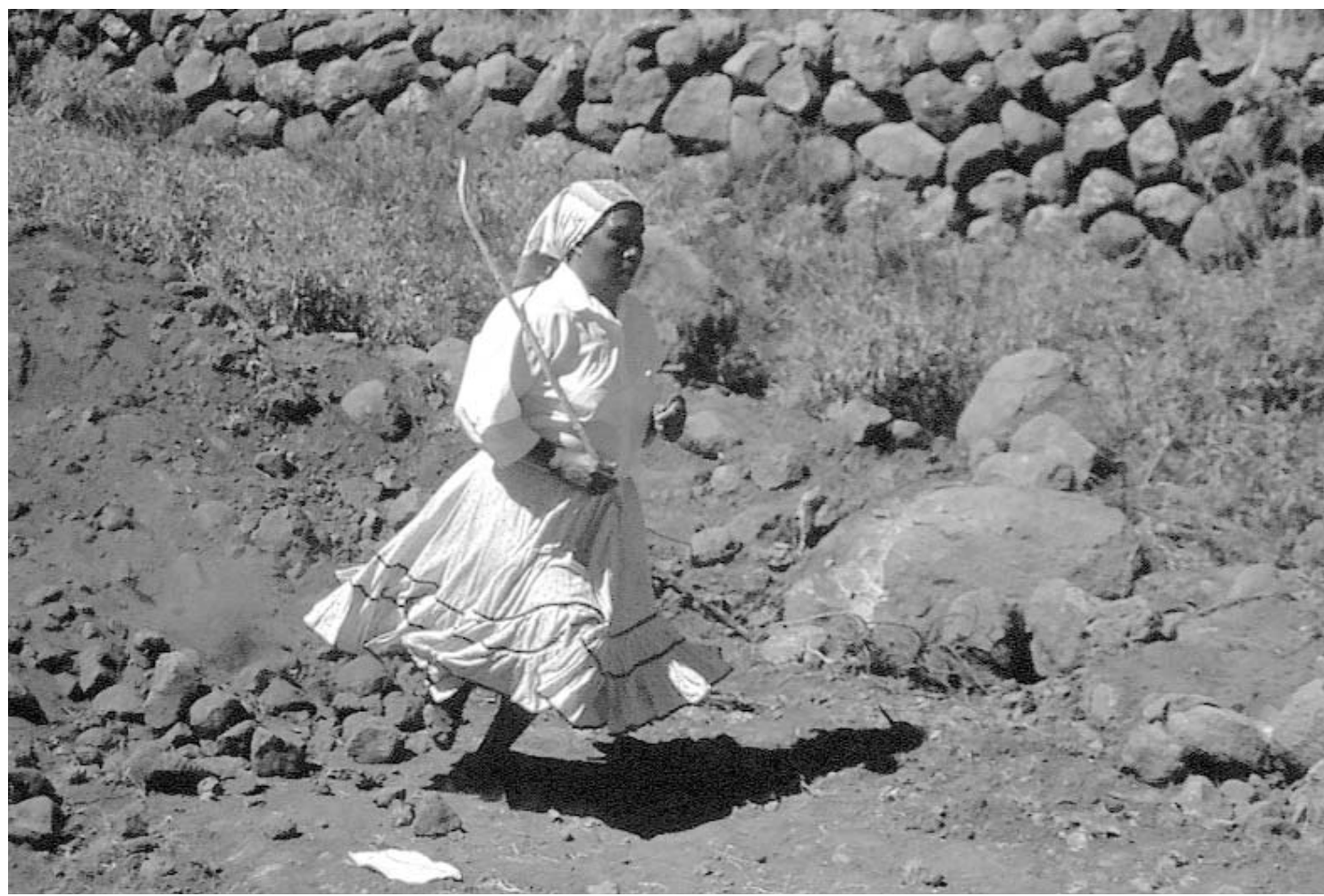

Carrera de ariweta en Cieneguita, octubre de 2001. Foto: Ángel Acuña Delgado.

cita. El owirúame o curandero les aplicará una cura de piernas mediante friegas con aceite o plantas medicinales y les administrará té de cedro.

Llegado el día del encuentro, el desarrollo de la carrera se atiene a unas reglas bastante simples. El circuito donde se corre puede ser circular, aunque con mayor frecuencia es lineal, de ida y vuelta sobre un trayecto de 6 a $30 \mathrm{~km}$ aproximadamente, ${ }^{11}$ utilizando caminos y senderos transitables más o menos pedregosos que discurren por relieves muy variables (meseta, barranca, bosque). Antes de dar la salida es preciso haber acordado la distancia del recorrido, la cantidad de vueltas, el número de corredores por equipo, ${ }^{12}$ las bolas o ariwetas de repuesto para

${ }^{11}$ Sobre un circuito de $6 \mathrm{~km}$ se pueden acordar de 20 a 40 vueltas, mientras que sobre uno de $30 \mathrm{~km}$ se acuerdan de cuatro a ocho.

${ }^{12}$ Siempre son dos las partes o bandos enfrentados pero éstos pueden estar compuestos por uno, dos, cuatro o seis corredores(as). En utilizarlas en caso de rotura o pérdida. Junto a la línea de salida, que además sirve de meta y ocupa un lugar central en el circuito, se coloca una hilera de piedrecitas a la que se le irán restando una tras otra, a medida que se vayan completando vueltas. La indumentaria no guarda nada de particular: el vestido utilizado es el normal de la vida diaria y éste ha cambiado a lo largo del tiempo; lo que se mantiene es el cinturón de cuero con pezuñas de venado colgadas a modo de sonajero, con el que corren algunos hombres, así como la banda de tela ajustada a la frente que llevan tanto hombres como mujeres. El calzado utilizado son huaraches (sandalias livianas con suela de caucho atadas al pie con una correa de cuero).

cualquier caso, lo normal es que destaque uno por equipo, haciendo el resto una labor de apoyo. 


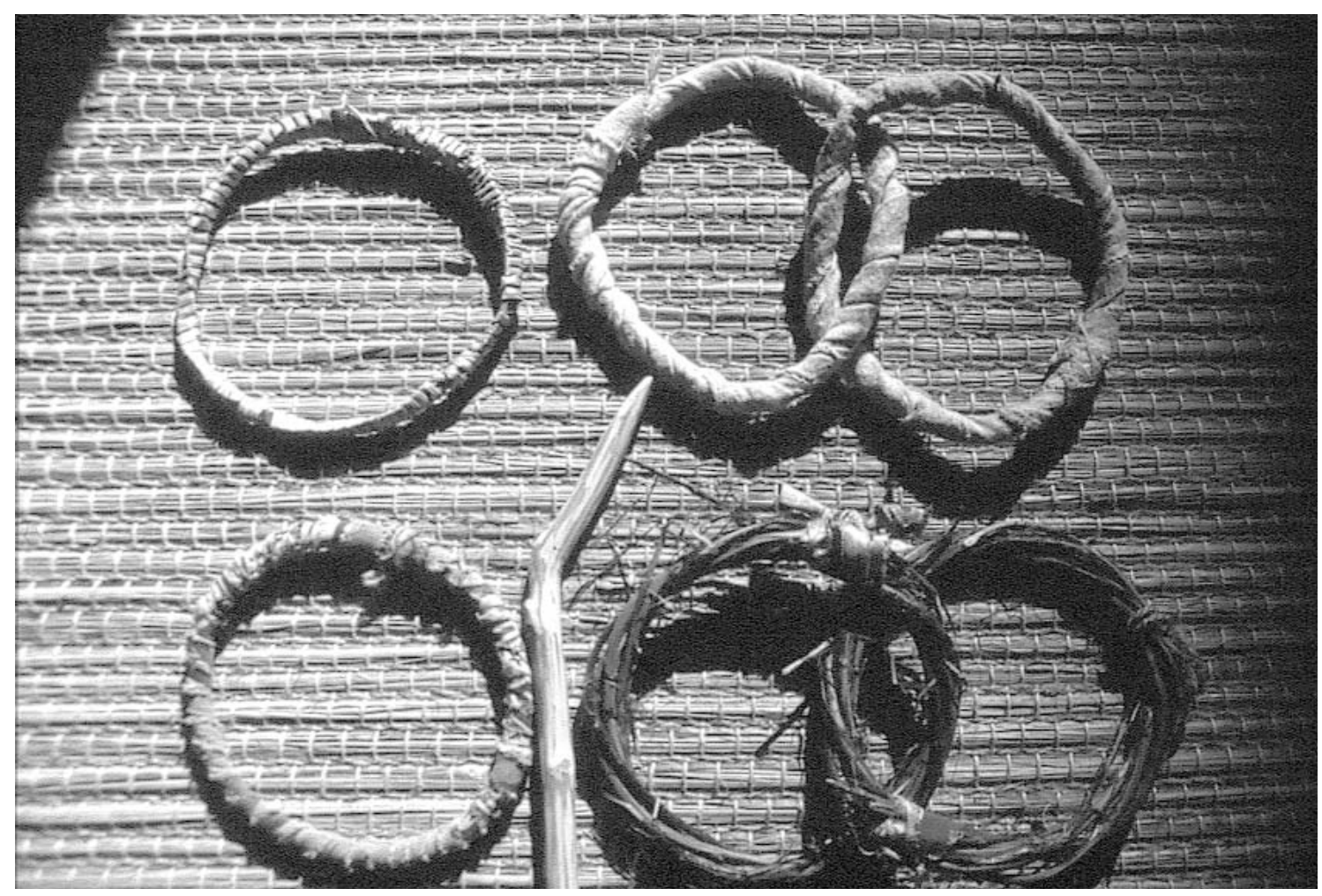

Ariwetas (rowera). Foto: Ángel Acuña Delgado.

La hora normal de comienzo se sitúa ente las 14:00 y las 15:0o h. Pasado así el medio día, los corredores salen con ritmo tranquilo, concientes de que la prueba no ha hecho más que empezar y de que aún queda mucho por andar hasta que se termine en torno a las 11:00 o 12:00 $\mathrm{h}$ del siguiente día. La técnica de carrera y lanzamiento tiene como principal finalidad parar lo menos posible, economizando al máximo la energía. Para ello, el hombre, con la misma inercia de la carrera, coloca el pie junto a la bola y la lanza con fuerza hacia adelante efectuando una parábola de $40050 \mathrm{~m}$; sigue corriendo hacia el punto donde cayó y repite así la operación una y otra vez hasta el final, procurando que no se salga de los cauces del camino, ya que al no poderse coger con las manos, toda salida supone pérdida de tiempo y esfuerzo extra. La mujer, por su parte, corre con una varilla de unos $70 \mathrm{u}$ $80 \mathrm{~cm}$ de largo, curvada por un extremo. Con ella recogerá la ariweta del suelo mientras corre, lanzándola fuer- temente hacia adelante 50 o $60 \mathrm{~m}$, siempre en el sentido de la carrera, evitando igualmente que salga de los márgenes del camino a seguir. Los corredores y corredoras aplican estrategias para desmoralizar al rival, colocándose por ejemplo tras él sin dejar que se separe mucho, estudiando sus movimientos para pasarlo al llegar el momento oportuno.

La carrera rarámuri es una tarea de equipo, donde es muy importante el trabajo en grupo para conseguir ganar. Es imprescindible el apoyo de una serie de personas que proporcionen agua y alimento (pinole) ${ }^{13}$ a los corredores, que los alumbren con antorchas de ocote por la noche, que los ayuden a recuperarse de posibles heridas o desfallecimientos, que les den ánimo, que vigilen el cumplimiento de las normas por parte del otro equipo.

\footnotetext{
${ }^{13}$ Maíz molido que se disuelve en agua.
} 
También el público cumple su papel, no sólo de apostante sino de animador, gritando ¡weriga! (rápido) a los suyos y siguiéndolos en algunos tramos del recorrido, vigilando asimismo que todo transcurra limpiamente. Muchos han apostado antes de dar comienzo la carrera, pero otros aguardan una o dos vueltas para ver cómo corren y entonces apuestan, siempre que haya quien la acepte, fungiendo siempre el chokéame de mediador.

Con frecuencia las grandes carreras concluyen antes de que se cubran todas las vueltas convenidas, debido a la diferencia entre los contendientes. Cuando un corredor estima que no podrá alcanzar al otro y se ve perdido, opta por abandonar y ahí acaba todo, dado que para ganar no siempre es preciso cruzar la meta el primero, basta con quedar por delante del otro en caso de abandono.

Sea como sea, concluida la carrera, al final del evento los corredores descansan, se alimentan, duermen junto a sus familiares y seguidores, sintiéndose unos contentos (los ganadores) y otros descontentos (los perdedores) por lo sucedido, pero sin exageración. Es normal también que los perdedores justifiquen la derrota apuntando momaléfica obrada por alguien. ${ }^{14}$ Incluso en casos extraordinarios se llega a insinuar que la carrera ha estado amañada al considerarse que el corredor que ha perdido lo ha hecho premeditadamente para hacer ganar a quienes han apostado por el otro.

El chokéame, o chokéames, sin tener nada anotado por escrito, reparte el contenido de las apuestas (dinero, enseres, animales) entre los ganadores. El/la ganador/a, que también ha apostado, recibe lo que le corresponde, además de la gratificación voluntaria ("barata") de las personas que así lo estimen; tras ello todos vuelven a sus lugares de origen.

${ }^{14}$ De manera nunca demostrada se refieren casos en los que alguien ha colocado huesos de muerto en el punto por donde pasa un corredor para que éste pierda fuerza. La presencia a veces de una persona señalada como sukurúame (hechicero), que se muestra partidario de un bando, puede hacer que el otro se empiece a sentir derrotado.

\section{FUNCIONES DE LA CARRERA RARÁMURI}

\section{La competencia deportiva}

Una primera función se deriva del sentido más inmediato que tiene la acción misma de correr. ¿̨Por qué se corre?, ¿cuál es el resultado final de la carrera?, ¿qué mantiene tanta expectación en el público asistente? El agonismo o competencia es un componente básico de la estructura y dinámica de la carrera rarámuri, instalado no sólo al nivel de los corredores sino también de quienes los apoyan.

La carrera entraña una dura competencia en donde no hay tregua, ambos contendientes pretenden ganar y llegarán hasta la extenuación por conseguirlo, pero ello no quiere decir que pierda el componente lúdico. Se trata de una competencia dura, sacrificada, pero también placentera, en donde se puede hablar de distintos grados de diversión al igual que de rivalidad.

La carrera se convierte en un acto divertido en la medida que se ve acompañada del lanzamiento de un objeto, tener que prestar atención a una bola de madera o a un aro vegetal para conducirlos en la dirección adecuada, constituye un entretenimiento que rompe con la monotonía de la carrera, dotándola de un componente lúdico que la llena de contenido. No tendría sentido correr sin bola, aunque algunos lo hagan en grandes competencias para rivalizar con los chabochis ${ }^{15}$ en su terreno y a su manera. La bola o la ariweta son elementos indispensables para que la carrera rarámuri sea pensada y sentida como una actividad lúdica y divertida, sin la cual carecería de valor e interés.

Diversión y sufrimiento no se dan aquí en una relación inversa. No porque la carrera sea larga y entrañe mucho sacrificio tiene que ser menos divertida para el corredor, sobre todo si éste siente que puede ganar. En las carreras pequeñas de niños o niñas o en las que acontecen durante las tesgüinadas, la inversión de esfuerzo no es grande y la diversión suele ser total para los corredores y corredoras como para el público que se encuentra

15 Término que significa "barbudo" y se le asigna al hombre blanco y mestizo. 
presente y las promueve, pero no menos divertida puede ser una gran carrera en donde el dolor por el desgaste físico se ve compensado por los logros que se pueden conseguir. La diferencia más bien estriba en que a medida que aumenta el grado de intensidad o interés de la competencia, el carácter divertido de la carrera tiende a situarse en una de las partes enfrentadas, la que gana; mientras que a menor rivalidad el jolgorio es más generalizado porque los que no han ganado, al fin y al cabo tampoco han perdido mucho en las apuestas, y "otra vez se ganará”.

En cualquier caso, independientemente del carácter fruitivo o placentero que esta práctica entraña para los corredores y el público, por tratarse de una costumbre cultural muy apreciada, una nota distintiva de la competencia es la templanza de ánimos por parte de los corredores una vez terminada la prueba. El que gana se muestra contento por haberlo conseguido pero no llega a ser exultante, no salta de alegría y menos aún se manifiesta arrogante o engreído, lejos de ello, asume su victoria con normalidad, como fruto de su esfuerzo personal, del apoyo de su gente y de la suerte de no haber tenido ningún percance. El deber y el deseo fueron cumplidos y se disfruta con los suyos sin exageración, tan "sólo se ha ganado una carrera", una entre tantas, aunque se traten de carreras excepcionalmente largas. El que pierde, por su parte, no le dará mayor importancia en los desafíos menores plenamente lúdicos, pero tampoco se mostrará deprimido si se trata de un gran reto en una carrera mayor, "simplemente se ha perdido una carrera" que otra vez se ganará, no hay que darle mayor trascendencia, era posible perder (como ganar) y ha ocurrido, puede disgustar por no cumplirse las expectativas pero no se le da más vueltas. En el plano deportivo competitivo, el hecho de ganar o perder no supone un cambio profundo en el estado de ánimo de los corredores ni se sienten superhombres o supermujeres; tampoco se hunden en el desconsuelo y en la frustración, el contento o descontento se produce sin exageración. ${ }^{16}$

16 Por la información obtenida, son las consecuencias económicas de la carrera las que se dejan sentir más a la hora de ganar o perder, sobre todo en el público apostante. Según Don Burgess: "La idea de ganar
Sea como sea, el carácter agonístico de la carrera rarámuri, el enfrentamiento no violento que se produce entre los contendientes cumple con una función bastante generalizada en el deporte, tanto antiguo como moderno, que es la liberación de agresividad. Las tensiones sociales tienen como cauce de salida las tesgüinadas; en ese escenario surgen conflictos y se desatan frecuentemente actos más o menos violentos que rompen con el sosiego y la paz que domina la vida rarámuri. Pero además de las tesgüinadas, en donde la agresividad se hace explícita de una manera violenta, las carreras sirven también para liberar tal agresividad, para encauzarla, dirigirla y hacer que salga sin necesidad de que se manifieste violentamente. Los corredores y corredoras pueden verter su rabia acumulada, en caso de existir, gastando energía corriendo hasta no poder más, lanzando con fuerza la bola o la ariweta, y el resto de los participantes lo pueden hacer acompañando a los corredores en parte del trayecto, emitiendo gritos de ánimo, apostando. De cualquier modo, la carrera se ofrece como una oportunidad para desprenderse de tensiones, bien corriendo o proyectándose en los corredores, funcionando así a modo de válvula hidráulica que regula de manera culturalmente aceptada la sobrepresión acumulada en la cotidianidad. Así, la carrera es una manifestación motriz lúdico-competitiva y fuertemente arraigada en el modo de ser rarámuri, que atrae mucha expectación no sólo por su carácter divertido y agonístico, sino por las implicaciones que conlleva en otros planos de la cultura que sobrepasan la simple competencia entre corredores.

\section{La apuesta económica}

La apuesta forma parte de la carrera y es uno de sus grandes alicientes, incluso cabría decir que para muchos

está relacionada con la de recibir o ganar favor. El verbo que se usa en el idioma rarámuri para expresar la idea de ganar favor de Dios, de ganar un juego y de ganar comida para trabajar, es el mismo, mépua, ganaremos. También las palabras ganar y perder tienen la misma raíz, me. La palabra perdimos, métirú, es la forma pasiva y da la idea de 'fuimos ganados' o 'nos ganaron'” (Mares, A. y Burgess, D., 1996: 55). 
es el más preciado, si nos atenemos a las conversaciones mantenidas con los propios rarámuris, quienes afirmaban recurrentemente que terminada la carrera todo el interés se vuelca hacia las apuestas y no en los exhaustos corredores a los que no se les presta demasiada atención, dejándoles simplemente que se recuperen sin mayores agasajos.

La apuesta en la carrera no supone una forma de ganarse la vida, no existen personas que basen su sustento y el de su familia en los beneficios obtenidos de las apuestas; lo que sí entraña es una forma de transacción económica, de obtención de recursos, sobre todo si se cuenta con un buen corredor. La familia y aún la comunidad que tenga un corredor ligero puede invertir parte de sus recursos para duplicarlos, aunque nunca sea un valor seguro al cual agarrarse y que la posibilidad de la pérdida se mantenga siempre presente. Al tener la sociedad rarámuri una economía de subsistencia, doméstica, de autoconsumo, la apuesta en las carreras permite la circulación de bienes en esferas intra e intercomunitarias y aun interétnicas. Los bienes cambian de propietario, unas ve- apuestas se convierte en un espacio de transacciones, donde se ponen en juego bienes de uso y consumo, una bolsa de valores donde dichos bienes se arriesgan ante la disyuntiva de doble o nada.

Por otro lado, la gran anomalía que a veces se deja sentir en la carrera, y que pervierte la confianza de los participantes en la misma, acontece precisamente por la apuesta. Es en razón a la apuesta por lo que algunos corredores se dejan sobornar, pierden premeditadamente una carrera para beneficiarse económicamente de la mis$\mathrm{ma}$, al igual que quienes los inducen a hacerlo, los cuales son con diferencia los más beneficiados. Es la apuesta la que acrecienta el valor deportivo, económico y social de la carrera, la que hace que adquiera mayor interés y al mismo tiempo, la que contribuye en algunos casos a su perversión, cuando por ella se cometen trampas.

No hay que perder de vista, no obstante, que los propios corredores son igualmente apostantes, por lo que ganar o perder la carrera de la que son protagonistas implica asimismo ganar o perder la apuesta. Esto aporta un valor añadido a la competencia física, un valor económico del que se pueden beneficiar o perjudicar, siendo preciso estar motivados para rendir al máximo que permitan las fuerzas. La apuesta económica de la que participan los propios corredores constituye así un importante incentivo para mantener el ánimo de éstos, ya que además del prestigio como corredor están en juego bienes materiales, y una prueba de credibilidad para el resto del público, ya que se supone que cada bando hará todo lo posible por ganar, al comprobarse que los corredores o corredoras han apostado importantes bienes a su favor.

\section{El encuentro social y el soporte ideológico}

Con un patrón de asentamiento tan disperso, la vida rarámuri discurre de manera bastante aislada, la comunicación interfamiliar es escasa y pueden transcurrir semanas enteras sin que en algunos ranchos se haya entablado relación que vaya más allá del grupo doméstico. Ante este panorama, las reuniones dominicales para ir a misa y escuchar el sermón o discurso del siríame, así como las reuniones de trago o tesgüinadas constituyen dos me- 
dios institucionalizados para no perder el contacto, mantener los vínculos, transmitir y adquirir conocimientos, y hacer posible la socialización. En ese sentido, las carreras de bola y ariweta propician el encuentro y la integración social, convirtiéndose en un tiempo para compartir experiencia, para intercambiar impresiones y salir de la monótona vida independiente. Son muchos los testimonios rarámuris que destacan el valor social de la carrera por encima de todo; lo más importante no es ganar sino encontrarse para mantener la comunicación, como se desprende del siguiente relato rarámuri:

La apuesta no tiene que ver mucho, se apuesta más bien por conseguir algo, por lograr algo, pero más el espíritu en el fondo es de la competencia, de tener rivalidad con otros pueblos y mantener la comunicación, porque muchas veces hace tiempo que no se ven y es en las carreras cuando se vuelven a ver y para platicar, y ahí mismo se concertan nuevas carreras, entonces el objetivo de esto es mantener la comunicación continua con otros pueblos (entrevista a J.M.P.).

No hay que circunscribir el componente socializante de la carrera; sin embargo, a partir del momento que ésta se convoca, a las 24048 horas todos se reúnen en el sitio de encuentro para que tenga lugar. Si bien las carreras pequeñas, muchas veces improvisadas, ocupan generalmente poco tiempo de interacción, aunque su mayor frecuencia de realización hace que estos momentos sean más numerosos, las grandes carreras entrañan un proceso organizativo muy elaborado donde cada cual interacciona con los demás desde su respectivo papel. Los chokéames de ambos bandos se visitan para ir concretando diversos extremos de la carrera, a la vez que la promueven e incitan a la gente a que apueste. Los corredores son bien cuidados por sus partidarios, por su familia, por el owirúame, por el chokéame, concientes del compromiso que adquieren con ellos para hacer todo lo posible por ganar y así mejorar algo la situación económica de los suyos. Los seguidores de ambos bandos cuentan con varias semanas para conversar sobre la carrera, siendo ésta un importante motivo para comunicarse y llenar el tiempo. Unos y otros ocupan distintas posiciones ante el anunciado evento y desempeñan de la mejor manera sus papeles con un elevado contenido socializante.
La carrera se presenta así como un acontecimiento social que propicia el disfrute colectivo al poseer un claro componente recreativo y no sólo competitivo, capaz de atraer la atención de nuevas personas que incluso han realizado recorridos de varios días para acudir a la cita. Además, supone un evento cargado de estímulos que no sólo refleja sino que también reproduce algunos de los valores más importantes del grupo; con la carrera se recuerda que hay que ser hábil, inteligente, solidario y muy resistente para conseguir los objetivos que se persiguen.

Pero no sólo en la carrera se aprecia la recreación de la identidad étnica al reproducirse un comportamiento tradicional que vincula al grupo dándole sentido de pertenencia, el hecho de compartir una manera peculiar de relacionarse con la carrera pedestre es una manifestación más para marcar la diferencia entre el "nosotros" y los "otros": nosotros corremos con bola o ariweta, los otros corren sin ella.

Es importante no perder de vista que se trata de una carrera en la que se enfrentan dos corredores/as o dos bandos; los rarámuris deben decantarse por alguno de ellos siendo ese un ejercicio que supone una adscripción diferencial. En ese sentido, nos contaban que si bien es normal apostar por el corredor o corredora al que se considere mejor preparado, independientemente de la simpatía que cause o de la afinidad que se tenga con él o ella, se da también el caso de apostar incondicionalmente por aquél con el que se mantiene una mayor proximidad, por el que es pariente o vecino de uno, que pertenece a la misma ranchería, siempre y cuando éste dé las mínimas garantías de victoria. Esta segunda circunstancia se suele dar más cuando se enfrentan corredores de rancherías muy distantes, lo cual hace que el público asistente apueste por quien o quienes representan a su lugar de procedencia: en caso de enfrentarse corredores de Choguita y Panalachi, los residentes de Choguita tenderán a apostar por su corredor, mientras que los de Panalachi lo harán por el suyo, sin que se fuerce a nadie a hacerlo. ${ }^{17}$

\footnotetext{
17 Sobre la fuerza socializante de la carrera rarámuri escribía W. Bennett: "Una gran carrera, entre pueblos, es uno de los factores que tienden a unir a las comunidades. La gran carrera va acompañada de una fiesta en la que ambos bandos se juntan. Las apuestas, el incan-
} 
No obstante, si bien el encuentro social en una gran carrera divide a los partidarios de uno y otro bando, creando un ambiente festivo de rivalidad, no parece que ello sea óbice para generar animadversión entre los dos grupos de seguidores; lejos del ambiente hostil que en la sociedad moderna se crea entre las aficiones de dos equipos deportivos que se enfrentan, en la carrera rarámuri todo acontece de manera más tranquila $y$, a menos que se violen las normas o haya problemas con el reparto de las apuestas, el conflicto no suele aparecer y menos aún brotes de violencia. La no trascendentalización de la carrera, el no verla como una cuestión de honor donde vaya en juego la vida, el no sacarla fuera de los márgenes que supone la competencia física, hace que la rivalidad entre los bandos se exprese en las apuestas y en la animación diferenciada por parte de los seguidores, sin que ello merme la cohesión social en términos generales.

Claro que toda norma tiene su excepción y a veces se escuchan anécdotas que hablan del enfado de una parte de los apostantes cuando la otra retiró lo apostado antes de concluir la carrera, o la riña de alguno al denunciar que el corredor ganador no cumplió cierta regla. Aun así, los perjudicados toman nota de lo ocurrido para no confiar más en ciertas personas, solucionándose los posibles problemas surgidos a través del diálogo o por medios pacíficos ante la autoridad competente en cada caso (chokéame, siríame). ${ }^{18}$

Dentro de la función ideológica sustantivada en el papel identitario de la carrera rarámuri, cabe incluir también el apoyo a las creencias religiosas que se reafirman con la participación en las carreras. Para correr bien es preciso encontrarse a gusto consigo mismo, sólo así se puede confiar en la victoria, el alma o las almas deben

sable estar mirando y alentando a los corredores y el entremezclarse con distintas personas, desempeñan una doble función: primero, ponen en relación a dos comunidades; segundo, unifican a cada comunidad. La competencia definitivamente crea un grupo 'nosotros' y un grupo 'ellos'. El hecho de que, tanto los corredores como sus respectivos pueblos que los apoyan, apuestan, une al bando de los 'nuestros' de manera decisiva. Sin embargo, las grandes carreras no son lo bastante frecuentes para convertirse en un factor de importancia mayor" (Bennett, W. y Zingg, R., 1935, 1978: 503).

${ }^{18}$ La norma de conducta pacífica siempre es posible de alterarse cuando aparece el alcohol, sobre todo destilados de alto grado. estar presentes y en paz, cualquier remordimiento o mala conciencia puede ser causa de debilitamiento y de la pérdida de la carrera. Según Don Burgess, "los rarámuris no separan nada de su dimensión religiosa” y agregaba: "me han platicado que cuando corren lo hacen para Dios" (entrevista a D.B.). Los motivos espirituales no dejan de estar presentes en algunos para participar en una carrera, como nos decía un rarámuri de Rejogochi: "Uno participa para que Dios nos dé más vida por lo que está haciendo, no para ganar dinero, uno le echa ganas por la vida de otras personas también, para que Dios esté contento junto a nosotros" (entrevista a M.Ch.).

Además de ello, en las carreras con frecuencia se hace presente la creencia en la existencia de fuerzas poderosas sobrenaturales que pueden manejar u operar a favor o en contra de otras personas. La creencia en el bien realizado por el owirúame (curandero) con la aplicación de remedios medicinales, y en el mal causado por el sukurúame (hechicero) que supuestamente ha realizado algún maleficio, están muy presentes, así como el respeto e incluso temor que se le tiene a estas personas, que suelen ser solitarias y atípicas, manteniendo con ellas un trato cordial pero no excesivo. La carrera pone así a prueba estas creencias y su adhesión a ellas.

Un aspecto importante a destacar es el papel que posee la carrera como vehículo de acercamiento de la sociedad mestiza a la rarámuri. ${ }^{19} \mathrm{La}$ Sierra Tarahumara ha experimentado una fuerte colonización mestiza, sin embargo, aunque la sociedad mestiza ocupe en este caso la posición dominante, se puede apreciar en ella adaptaciones de algunas formas de comportamiento rarámuri. No son pocas las personas que se sienten atraídas por el modo de ser y estar rarámuri y adoptan ciertas conduc-

\footnotetext{
${ }^{19}$ Como señala J. Kennedy (1970), que llegó a la Tarahumara en noviembre de 1959, un tipo de oportunidad para el contacto interétnico sucede en las carreras internas y entre pueblos que organizan los rarámuris: "Los mestizos se divierten asistiendo a ellas; participan en las apuestas y con frecuencia aprovechan la oportunidad para vender cigarros, fruta, u otros productos. En ocasiones participan en la carrera sirviendo como apuntadores, es decir, acompañando a los corredores y poniendo la pelota frente a ellos para que la pateen en las últimas etapas de la carrera. La interacción en las carreras no es estrecha, ya que a pesar de bromear frecuentemente con los indios, los mestizos tienden a formar un grupo aparte." (Kennedy, J., 1970: 30).
} 
tas integrándolas a su propio estilo de vida, entrando en un proceso que podríamos denominar como "raramurización del mestizo".

La carrera constituye una de esas prácticas que acaparan el interés del mestizo. Se acercan a ella no sólo para apostar, sino para disfrutar de ella apreciando sus valores; incluso hay casos de mestizos corredores de bola ${ }^{20}$ que al contar con una buena forma física han competido entre ellos mismos y aún con los rarámuris, ganándoles. Un caso muy significativo es el de Rafael, hombre de 60 años residente en Creel, que aprendió a correr con bola a los 21, acompañando a los corredores tarahumaras (como él mismo los designa) amigos, ayudándolos en el recorrido, colocándoles la bola en el camino para hacer que ganara la apuesta su hermano mayor. Así fue aprendiendo y llegó a correr grandes distancias de más de $120 \mathrm{~km}$ con éxito. Hoy cuenta con placer y cierta melancolía su experiencia en las carreras, insistiendo en el ambiente festivo que se creaba y en las lecciones de honestidad que recibió continuamente de los rarámuris al correr con ellos. Asimismo señalaba el uso interesado que han hecho los chabochis (hombres blancos), quienes las han utilizado con el exclusivo fin de sacar dinero de ellas.

\section{RESISTIR PARA VIVIR}

La carrera rarámuri se puede analizar desde distintos puntos de vista, pues está cargada de valores y estos le infunden diferentes lógicas. Uno de los principales valores a destacar es el de la resistencia en sentido amplio; pero, ¿por qué se valora tanto la capacidad de resistencia?

Tanto hombres como mujeres han de mostrar aguante no sólo en la carrera sino en todos los órdenes de la vida, hay que resistir bailando matachines toda la noche, hay que soportar el frío nocturno y el invernal con lo que se lleve puesto en el momento; hay que aguantar el hambre si no se tiene qué comer durante días, o la sed si no se dispone de agua en una larga travesía, o el parto na-

${ }^{20}$ No se tiene noticias, sin embargo, de mujeres mestizas que hayan corrido con ariweta. tural, o el dolor de un traumatismo o de una enfermedad, y en otro orden de cosas, hay que resistir los envites del choque cultural.

La resistencia posee, pues, un importante valor social porque de ella depende su mantenimiento cultural e identidad étnica, de la voluntad de seguir siendo rarámuri. Concientes de su importancia, escuchábamos reflexiones o afirmaciones nativas que decían: " $i$ Hay que resistir para vivir!", "iquien no aguanta, no vale, se pierde, muere!", afirmaciones que se refieren a la vida en general y que tienen un claro reflejo en la carrera.

Pero, ¿cómo se consigue tener una capacidad de resistencia tan elevada en la carrera?, ¿cuál o cuáles son los factores desencadenantes? No son precisamente los grandes corredores quienes con sus palabras responden a tales interrogantes; caracterizados por un talante humilde y callado, no se puede esperar una respuesta explícita y razonada sobre estas cuestiones. Martimiano de Choguita, por decirnos algo, afirmaba confusamente que resistían tanto porque "comemos pinole y echamos aceite en las piernas". Los alimentos naturales, sin química, que habitualmente forman la dieta rarámuri: pinole, quelite, maguey asado, son frecuentemente apuntados como factores que contribuyen a formar un cuerpo fuerte y resistente, pero, ¿serán ésas las principales causas?

Junto con quienes piensan que llevar una vida ligada a la Naturaleza, con una alimentación sana y actividad física diaria es la clave para conseguir una buena preparación como corredor, se hallan algunos que consideran como clave del éxito tener el alma en paz y llevarse bien con Dios.

La fortaleza de las almas en los corredores facilita la buena predisposición para correr, el buen ánimo, la mentalización para ganar, la resistencia a ser objeto de algún maleficio, pero no asegura la fortaleza y resistencia física o la victoria en la carrera, la cual obedece a otras justificaciones. Como explica W. Merrill (1992: 149):

...la dureza y la fuerza de las almas no se reflejan tan directamente en el cuerpo. Un hombre joven puede tener un cuerpo fuerte y duro, que él fortalece con ejercicio y la exposición a los elementos, sin que sus almas sean igualmente fuertes y duras. A la inversa, una persona mayor puede tener almas fuertes y resistentes pero un cuerpo débil. 
La explicación más lógica para entender la extraordinaria resistencia desarrollada por los rarámuris para la carrera pedestre se apoya en su modo de vida, en la adaptación al entorno ambiental. Las largas caminatas por el monte, bien para cuidar los rebaños de chivas, para cazar o para visitar parientes o amigos son actividades frecuentes en la vida de este pueblo. Tanto niños como niñas desde muy pequeños adquieren la responsabilidad de cuidar los rebaños, los acompañan y conducen a las zonas más propicias para pastar o ramasear, pasando días y días fuera de casa, con los conocimientos y mentalidad suficiente para poder sobrevivir en situaciones que no serían fáciles de soportar para muchos. Desde pequeños se acostumbran a tener que aguantar las situaciones desagradables que vayan viniendo (frío, calor, hambre, sed, dolor), con frecuencia de manera imprevista, soportándolas como parte de la normalidad, de una normalidad en la que unas veces se tiene y otras no, en donde los tiempos de abundancia o equilibrio ceden a los de escasez.

La pauta de asentamiento disperso condicionada por la limitada capacidad productiva de la tierra o por el deseo de independencia familiar, obliga a caminar mucho y emprender largos recorridos de ida y vuelta para mantener la comunicación y el intercambio entre las personas. La única manera que tiene la mayoría de los rarámuris para visitarse, bien sea por el gusto de hacerlo o por satisfacer alguna necesidad comercial o sanitaria, es caminando; a falta de vehículo mecánico o animal de carga hay que hacer el trayecto a pie, y es así cómo las grandes distancias no entrañan temor por el cansancio. En las conversaciones con algunos rarámuris mayores apreciábamos cómo se hablaba con total normalidad de los trayectos de uno o dos días ininterrumpidos que unos y otros acostumbraban hacer, sobre todo en el pasado de hace unos 20 o 30 años, sin que le dieran la menor importancia. Aún hoy son muchos los que deben seguir cubriendo grandes distancias a pie para satisfacer sus necesidades vitales; son varios los niños del internado de Norogachi que con diez o doce años han de caminar durante ocho o nueve horas para ir a sus casas los sábados junto a sus padres que van a recogerlos, para regresar de nuevo al colegio-internado el lunes de madrugada por el mismo camino, y nadie se queja de tal situación, cada cual se acostumbra a las circunstancias que le ha tocado vivir.

Con un poco más de ritmo el caminar se convierte en correr, y si a la acción de desplazarse a pie se le añade el lanzamiento de una bola o un aro, dicha acción se convierte en juego; así el rarámuri puede conjugar en la misma acción el trabajo y el juego. La primera dimensión está caracterizada por el objetivo externo que persigue la acción: llegar a donde se tiene previsto, y la segunda, por el objetivo interno que se deriva de ella: divertirse, disfrutar de la acción misma. Un comportamiento cotidiano que en principio puede resultar cansado, monótono o aburrido, con algunos retoques se convierte en un juego; así, en vez de ir caminando durante horas de una ranchería a otra, muchos(as) niños(as) y jóvenes van corriendo con bola o con ariweta, recortando obstensiblemente el tiempo empleado, con ánimo alegre y además con la ilusión de ganar algo en la apuesta. Ésta es una forma de hacer más grata la vida.

Pero volviendo a la capacidad de resistencia, no sería riguroso sobredimensionar esta característica en los rarámuris y elevarlos a la categoría de superhombres o supermujeres. Los rarámuris son extremadamente resistentes en la carrera por el proceso de adaptación en el que están involucrados desde que nacen: la dinámica de la vida diaria, las inclemencias meteorológicas, la pauta de asentamiento, las labores agropecuarias, las características del relieve, su dieta alimenticia, su capacidad para saber esperar, no impacientarse, aguantar, resignarse, etc., conforman un modo de ser y de estar en el mundo que entraña una personalidad segura de sí misma, y con gran capacidad de sufrimiento. Es el contexto ambiental y cultural, sin olvidarse del histórico, el que nos ofrece las claves para entender las razones de la carrera rarámuri y de la resistencia que sus actores muestran. La resistencia o capacidad de aguante es, pues, una consecuencia de la adaptación al entorno ambiental y una condición necesaria para que la cultura rarámuri tenga continuidad en dicho entorno.

Además del uso de la bola o la ariweta en la carrera, las diferencias de perspectivas nos pueden hacer ver como una rareza, desde la sociedad moderna avanzada, el hecho de correr 180 o $200 \mathrm{~km}$ en competencia sin haber participado previamente en un entrenamiento específico 
en relación con la carrera. “Es una barbaridad!”, dirían algunos; "debe ser peligroso aventurarse a ello", pensarían otros; y es que realmente sería una temeridad, un peligro, si una persona habituada a la vida urbana y sedentaria se aventurara de pronto a correr tal distancia. Su salud correría seguramente un serio riesgo si se empeñara en hacerlo y en llegar hasta el final. Pero no es ése el caso rarámuri; no entrenar o ensayar específicamente la carrera en el periodo previo a una gran cita no es anacrónico, no está dentro de los planes del corredor, que si se le propone, posiblemente pensaría: “iPara qué malgastar energía con ensayos de carrera, con lo que cuesta conseguirla? ¡Hay que estar loco!” El rarámuri no actúa con simulacros ni considera necesario entrenar la carrera porque siempre está preparado de manera natural para ella, porque sería un despilfarro de energía (correr sólo por correr) y porque ganar o perder no es nada trascendental.

La lógica del entrenamiento específico, sistemático y controlado, destinado a conseguir el récord en la modalidad, la gloria personal y nacional, así como la fortuna, pertenecen a otro contexto muy distinto, a un contexto donde la carrera (como deporte) se transforma para algunos en un medio con el cual ganarse la vida, donde no importa el derroche de energía porque se dispone de ella en abundancia, donde la victoria o la derrota se viven con frecuencia como razón de Estado, y en donde dicha actividad es vivida por una elite de practicantes como un camino hacia la inmortalidad, y es legítimo pretender ser recordado por la historia, buscar trascender a través de la excelencia en una actividad así. Pero todo eso está muy lejos de la lógica rarámuri. Cada situación se explica y entiende dentro de su contexto, es una cuestión de perspectiva.

La carrera rarámuri tiene mucha vigencia como manifestación de la propia cultura; los rarámuris siguen corriendo grandes distancias aunque no haya tantos buenos corredores como antes. Sin embargo, lo que sí aparece como novedoso desde hace unas pocas décadas a esta parte, es la participación de los rarámuris en las carreras pedestres ultralargas organizadas por instituciones nacionales o internacionales, junto a los deportistas de elite llegados de diversos puntos del planeta. En estos casos, lo que se desprende de la participación rarámuri en las carreras pedestres no tradicionales es su biculturalismo, su actitud de situarse en el terreno del otro y hablar su lengua a través de la carrera, o incluso dentro de su propio territorio.

Históricamente han ido adoptando elementos culturales de los pueblos con quienes han tenido contacto, unas veces por préstamo, otras por imposición, pero han resistido en lo fundamental, en su estructura y dinámica social, en su visión del mundo. Ahora les está tocando correr como chabochis, pero sin imposición, libremente, para poder medir fuerzas con éstos, y a pesar de no ser precisamente su estilo, bien que lo saben hacer: en la ultramaratón de los cañones celebrada en Guachochi el 26 de julio de 1998, aparece en la portada de la revista "...en las carreras" (1998, 37): "Los tarahumaras dominaron"; y es que en la carrara de $90 \mathrm{~km}$ ganada por Martimiano ${ }^{21}$ (de Choguita), en la que participaron buenos corredores de distintos estados de México, especialistas en carreras ultralargas, de los diez primeros en llegar ocho eran rarámuris (cinco de Choguita, dos de Panalachi y uno de Bocoyma). Prueba en la que los rarámuris dieron a conocer una vez más su excelencia superando a corredores profesionales.

Sin embargo, ver correr a los hombres rarámuris sin bola por la barranca de la Sinforosa hará pensar a más de uno en que algo está cambiando en la Tarahumara, porque, como se dice desde la costumbre: "Hay que estar loco para correr sin bola o sin ariweta." ¿Qué está pasando? No se trata de locura, pero sí indica un proceso de cambio a través del deporte moderno que, en este caso, en forma de carrera, sirve como vehículo de comunicación entre culturas distintas, así como medio de aculturación por parte de la sociedad dominante que lo impulsa y a través de él reafirma sus valores. Sin perder de vista que la carrera rarámuri se halla repleta de significados y cualidades, como ya hemos apuntado, cabe preguntarse: ¿seguirán los rarámuris corriendo a la manera tradicional?, ¿por cuánto tiempo?, ¿se podrán mantener por tiempo

\footnotetext{
${ }^{21}$ Martimiano, como primer clasificado con 35' de diferencia sobre el segundo, hizo un registro de $8 \mathrm{~h} 23^{\prime} 39^{\prime \prime}$, lo que supone un ritmo medio de $10.7 \mathrm{~km} / \mathrm{h}$, ritmo aparentemente lento pero plenamente justificado por las grandes pendientes del terreno. 
indefinido la carrera tradicional y la moderna como expresión de la biculturalidad rarámuri?, ¿qué cambio de valores puede suponer cambiar la carrera tradicional por la moderna?, ¿es posible transferir los valores tradicionales rarámuris a una nueva manera de correr?

El tiempo irá dando respuesta a todas estas preguntas; de momento, los rarámuris, de una u otra forma siguen corriendo, siguen resistiendo y siguen sabiendo que "quien no aguanta, muere, desaparece", que "hay que resistir para vivir". Sin que concientemente lo pretendan, los rarámuris se mantienen en esa convicción y reflejan en la carrera, con toda su envoltura, buena parte de su ser al no tratarse tan sólo de una técnica corporal de desplazamiento sino de un hecho social y un símbolo de resistencia en amplios sentidos. Entendida así, desde una visión romántica de la cultura, en el caso rarámuri podríamos afirmar que ¡hay que correr para vivir!

\section{Bibliografía}

Amador, A., 1997, Tarahumara, Ediciones Agualarga, México.

Bennett, W. y R. Zingg, [1935] 1978, Los tarahumaras, una tribu india del norte de México, INI, México.

Damm, H., 1973, "Ejercicios deportivos de los pueblos primitivos", en Citius, Altius, Fortius, t. XV, fasc. 1-4.

Diem, C., 1966, Historias de los deportes, t. I, Diamante, Barcelona.

__, 1973, "Orígenes rituales", en Citius, Altius, Fortius, t. $\mathrm{XV}$, fasc. 1-4.

González Irigoyen, E., 1999, Diagnóstico colectivo de salud 1998-1999. Ejido de Choguita (municipio de Guachochi), Facultad de Medicina, UACH, sin publicar.
Instituto Nacional de Estadística, Geografía e Informática, 1995, Chihuahua. Conteo de población y vivienda, 1995. Resultados definitivos. Tabulados básicos, INEGI, Aguascalientes.

Irigoyen, F. y J. M. Palma, 1994, Rarajípari. La carrera de bola tarahumara, Centro Librero de Prensa, Chihuahua.

Kennedy, J., 1970, Inapuchi. Una comunidad tarahumara gentil, INI, ediciones especiales, núm. 58, México.

Lumholtz, K., [1904] 1972, El México desconocido, INI, México.

Mandell, R. D., 1986, Historia cultural del deporte, Bellaterra, Barcelona.

Mares, A. y Burgess, D., 1996, Re’igi Ra'chuela. El juego del palillo, ENAH, Chihuahua.

Mayer, G., 1996, Sobre los conflictos sociales, económicos, ecológicos e interétnicos en la Sierra Tarahumara del estado de Chihuahua, informe para la Secretaría de Relaciones Exteriores de los Estados Unidos Mexicanos, ENAH, Chihuahua.

Merril, W., 1992, Almas rarámuris, CNCA/INI, México.

Oros, S., 2001, Diagnóstico de salud: Capt. Santa Cruz y Cocherare (Norogachi, Guachochi, oct. 2000-feb. 2001), Facultad de Medicina, Universidad Autónoma de Chihuahua, sin publicar.

Paredes, A., R. L. Berger, y C. C. Snow, 1970, "Biosocial Adaptation and Correlates of Acculturation in the Tarahumara Ecosystem", International Journal of Social Psychiatry, vol. 16, núm. 3, pp. 163-174.

Pennington, C., 1970, "La carrera de bola entre los tarahumaras de México. Un problema de difusión”, América Indígena, vol. XXX, núm. 1.

Revista ...en las carreras, núm. 37, septiembre, Chihuahua. Sariego, J. L., 2000, La cruzada indigenista en la Tarahuma$r a$, tesis de doctorado en ciencias antropológicas, ENAH Chihuahua.

Schalkwijk, B., L. González, D. y Burgess, 1985, Tarahumara, Chrysler, México.

Weule, K., 1974, "Etnología del deporte”, en Citius, Altius, Fortius, t. XVI, fasc. 1-4. 